\title{
Numerical Investigation of the Performance of Solar Collectors
}

\author{
Muhammad Ayaz Akbar 1, *, Hafiz Muhammad Awais ${ }^{2}$, Muhammad Mubashir Naveed ${ }^{3}$, \\ Hafiz Abdul Saboor ${ }^{3}$, Dr. Tareq Manzoor ${ }^{2}$ \\ ${ }^{1}$ Department of Mechanical Engineering, The Hong Kong Polytechnic University, Hong Kong SAR \\ ${ }^{2}$ Department of Mechanical Engineering, COMSATS University of Science and Technology, Islamabad, Pakistan \\ ${ }^{3}$ Department of Mechanical Engineering, Dalian University of Technology, Dalian, PR China
}

Email address:

mayazakbar2@gmail.com (M. A. Akbar),ranaawais487@gmail.com (H. M. Awais)

${ }^{*}$ Corresponding author

\section{To cite this article:}

Muhammad Ayaz Akbar, Hafiz Muhammad Awais, Muhammad Mubashir Naveed, Hafiz Abdul Saboor, Dr. Tareq Manzoor. Numerical Investigation of the Performance of Solar Collectors. International Journal of Mechanical Engineering and Applications.

Vol. 8, No. 6, 2020, pp. 139-144. doi: 10.11648/j.ijmea.20200806.13

Received: November 9, 2020; Accepted: November 26, 2020; Published: December 4, 2020

\begin{abstract}
Solar energy is the most abundant form of energy on this planet. In Europe and other countries with relatively low temperatures, where hot water is one of the basic needs for human beings, solar collectors are used to fulfilling their needs. In this paper performance of the solar collector will be analyzed using ANSYS software. Under specific conditions, different analyses will be performed to evaluate the performance of a solar collector containing water as heat transfer fluid. A Computational Fluid Dynamics, CFD analysis will be performed to check the heat transfer capability of copper $(\mathrm{Cu})$ and aluminum (Al). The surging temperature could cause deformation, so in this paper, ANSYS structural software will be used to analyze the sustainability of structure under solar heat, so the performance of each material in solar energy applications can be estimated. After these analyses, we will be able to predict the maximum output temperature accurately we can obtain at a different time of the day, and each temperature we will analyze the maximum deformation within the structure because the pipes of solar collectors are not usually too thick, so the selection of material for the pipe is crucial. The purpose of this work is to simulate the performance of solar collectors under specific conditions and understand the temperature distribution along with the collector and also analyze the deformation we can obtain at different temperatures.
\end{abstract}

Keywords: Solar Collectors, ANSYS, CFD, Structural, Heat Transfer

\section{Introduction}

Researchers are finding alternate energy sources to overcome the energy crisis and to avoid the climatic change due to the burning of fossil fuels for getting energy [1]. Solar energy is one of the most effective renewable energy sources with effective intensity power of $1016 \mathrm{~W}$ receiving on earth's surface after losses, whereas globally $1013 \mathrm{~W}$ of electric power is required [2]. The solar collector is a kind of heat exchanger wherein heat exchange takes between a distance source and a heat transfer fluid flowing in the collector [3]. Solar radiation from the sun hits the absorber plate of the collector, and the thermal energy is then transferred to the fluid. Based on their design, solar collectors can be classified as concentrating and non-concentrating type. No concentrating class can be further divided into flat plate collector and evacuated tube collectors. Flat plate collectors are the most common type of collectors and the most primitive too. Work of Hottel and Woertz [4] in 1942 and by Hottel and Whiller [5] in 1958 can be looked like the first work on solar flat plate collector. They had developed the collectors consisting of a black flat plate absorber, a transparent cover, heat transfer fluid and an insulating case.

Tabor [6], in 1955, employed selective black surfaces to increase collector efficiency. His experiments on optical concentration revealed the ability of optical concentration to produce high-pressure steam. Many studies have been done after that to analyze and improve the thermal efficiency of 
the collector. Due to growing energy problems, solar energy has been looked at as a source of infinite power. Solar collector has significantly been studied in this matter. Many of the new designs have been developed after 1990. Various research works are being carried out over the world to improve the thermal performance of flat plate collectors. Polymers are used to build novel collectors to reduce weight. The use of Nanofluids makes the collectors compact by giving the same output as that of prominent collectors but in a comparatively smaller size [7] because Nanofluids possess much better characteristics and can be used in many thermal management systems [8]. Studies are also focused on finding the optimum spacing between the glass covers in the multiglazed collector. Indoor and outdoor tests are carried out based on the operating and design parameters to obtain the best possible system for desired working conditions. It is essential to decrease the heat loss from the collector to increase efficiency. Many studies are oriented in this direction to study and reduce heat loss, with increased glazing, honeycomb maze-based absorber plate, considering wind velocity in the Analysis of collector, etc. Analyzing the performance of the collector is equally vital as it helps to develop further and improve the design. Development and Analysis always go hand in hand. Experimental Analysis of all the different collectors produced is not feasible. Hence analytical and numerical methods have been employed to analyze the behavior of collectors in other conditions approximately. CFD codes have helped researchers to a great extent. Ability to reduce lead time, to study system under hazardous condition and study of controlled experiments of systems which are difficult or impossible to perform practically are some of the unique advantages of CFD.

Currently, most scientific research is focused on reducing the consumption of fossil fuels such as coal, oil, and natural gas, on reducing the impact of greenhouse gases released. In the atmosphere, the largest source of renewable energy available on Earth is solar energy. However, only a fraction of solar energy, in the form of daylight and photosynthesis, is used throughout the world. One-third of solar radiation is incorporated into space, and Earth, oceans, and clouds absorb the rest. It is very reasonable to collect solar energy to convert it into heating or cooling. Solar energy processes have little impact on the environment. In addition to environmental awareness, the decline of conventional energy sources has led to solar energy being the most appropriate energy source to meet the growing energy demand worldwide. Scientists have researched and developed technology for collecting solar energy for the benefit of humanity and are still considering the use of innovative technology to maximize the collection and use of solar energy. Among these technologies, solar heaters and collectors have attracted much attention due to the direct transformation of solar energy into thermal energy. The absorbed solar radiation is converted to heat and transferred to the heating process with liquid, usually water. The integration of solar energy into the building system and mechanical systems can reduce the cost of solar energy systems while improving the efficiency of the museum. Therefore, research on the design of integrated solar systems for buildings began in the early 1960s and continues today. In an integrated solar design, the building is used as part of the solar system. Solar Collectors usually consists of Pipes, absorber and a sheet but the most important is pipes and pipe's material. Nowadays, selecting a material is an important task, and in this kind, this research is one of a variety. We will analyze different material and their performance (CFD + Structural). We will study different heat fluxes from the sun throughout the day, how every material reacts, and how much deformation we can get under particular heat. Salma Marrakchi used parabolic type solar Collectors to simulate the performance by using CFD to analyze three-dimensional temperature distribution [9]. In previous paper used the simple solar collector to simulate the working of the solar collector by CFD [10]. A. A. Hachicha et al. tested the influence of the wind flow on the optical performance of the collector and thermal efficiency [11]. Yanjuan Wang et al. investigated the temperature effect on the deformation of HCEs under the non-uniform distribution of solar radiation using a three-dimensional thermo-mechanical coupling model [12]. Different approaches have been used to analyze different types of collectors [13-15]. In this paper, we used a unique approach to analyze the performance of collectors. We performed CFD and Structural Analysis to study the structure performance; the pipes used in collectors are not too thick, and the increase in temperature can cause deformation within pipes, which can lead to failure.

In this paper, two materials are chosen for the Analysis, Copper, and Aluminum. Copper has commonly used materials in such applications, so we will be evaluating its performance based on the application. In this paper, two analyses will be elaborated, Computational Fluid Dynamics (CFD) Analysis and Structural Analysis. CFD Analysis will show us the heat transfer phenomenon of both materials according to the heat we are receiving. Structural Analysis will show us the structural performance of materials under heat applied and how much deformation we can expect under such conditions.

\section{Methodology}

The software predefines the method. The followed method is described in the flow chart below.

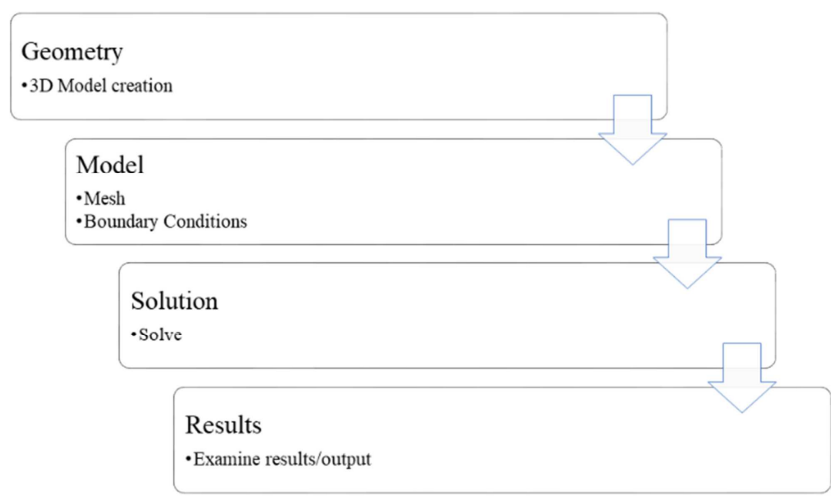




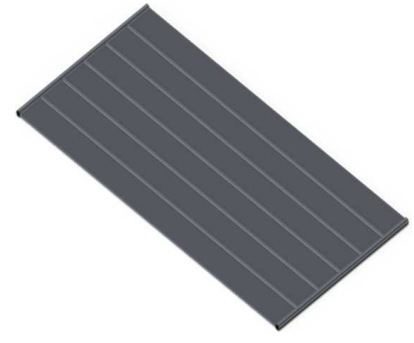

Figure 1. Geometry.

\section{Geometry}

ANSYS Fluent has a sub software to draw a model (3D or 2D), but it also can import external models made by using any other software (Solid Works, Pro E, AutoCAD, CATIA, etc.). The model used for this Analysis is created by using Solid Works. This model consists of mainly two parts - one as solid, which is the absorber plate, including pipes web. The second is pipes themselves created with an inner diameter of the absorber plate, which acts as a fluid domain for the water.

\section{Model}

Fluent has the second step as the model. The model further has sub-steps. During modeling, we mesh the geometry and apply boundary conditions.

\section{Meshing}

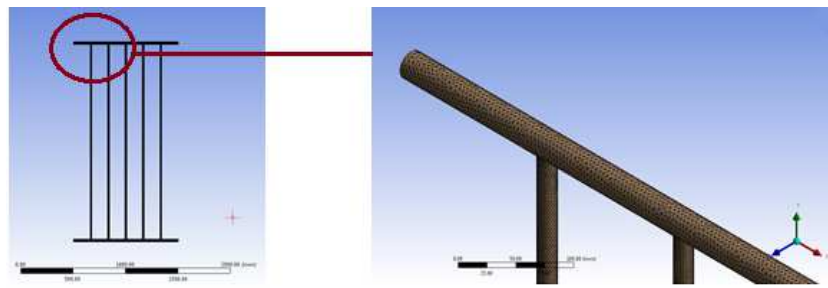

Figure 2. Mesh

Geometry is first imported to ANSYS, and then we choose the meshing standards according to shape. If meshing is much finer, the results will be less arguable.

\section{Boundary Conditions}

Boundary conditions are defined as the operating parameters. Our model is $3 \mathrm{D}$ in shape, and some assumptions are also made to solve this model.

1. The $3 \mathrm{D}$ model is in a state of equilibrium.

2. The ambient temperature is considered constant.

3. Surfaces other than the facing solar irradiance are assumed to be completely isolated.

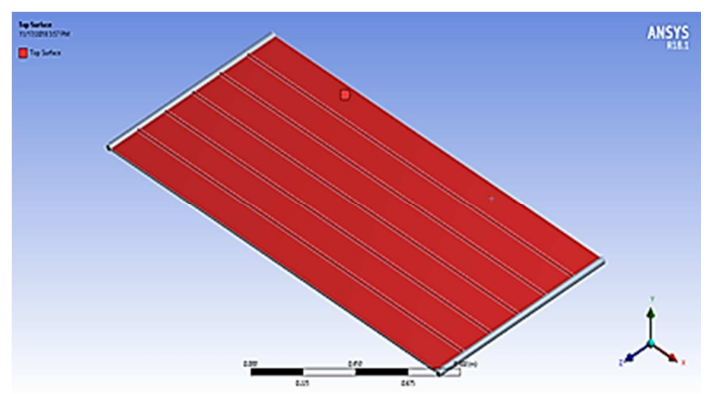

Figure 3. Top Surface.

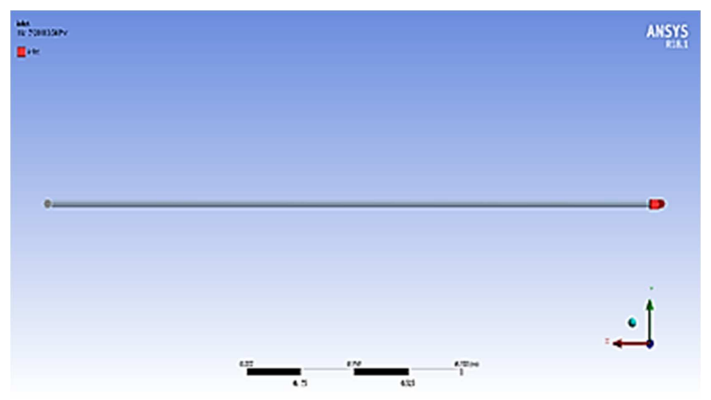

Figure 4. Inlet.

Boundary conditions applied to the specific model shown are explained below.

Inlet: Inlet is chosen as velocity inlet, and velocity of our fluid (Water liquid) is kept constant as $0.02 \mathrm{~ms}^{-1}$.

Top Surface: Top surface is the area where we are assumed to be receiving solar irradiance; with each passing hour of the day, we have a different value for solar irradiance.

Walls: Walls of the plate are the source for convection heat transfer. Convection heat transfer is assumed to be natural.

This performance evaluation is based on software analysis, so we using software we cannot assume the real environment; we need to perform this simulation based on some assumptions. So, mentioned are the assumptions used in this paper. These mentioned assumptions are for CFD analysis only. Predefined properties of copper and aluminum are presented in table 1.

1. Steady state Heat transfer

2. Model is in equilibrium

Table 1. Material properties.

\begin{tabular}{lll}
\hline Material & Specific Heat (J/Kg-K) & Thermal Conductivity (W/m-K) \\
\hline Aluminum & 910 & 250 \\
Copper & 390 & 401 \\
\hline
\end{tabular}

Table 2. Heat flux and ambient temperature at different hours of the day.

\begin{tabular}{lll}
\hline Time & Heat Flux $\left(\mathbf{W} / \mathbf{m}^{\wedge} \mathbf{2}\right)$ & Ambient Temperature $(\mathbf{K})$ \\
\hline $9: 00$ & 621.7 & 301 \\
10:00 & 750.51 & 305.7 \\
11:00 & 879.5 & 308 \\
$12: 00$ & 909 & 309.9 \\
$13: 00$ & 948 & 312.5 \\
$14: 00$ & 909.5 & 311.9 \\
15:00 & 790 & 309 \\
16:00 & 597.5 & 306 \\
17:00 & 357 & 304 \\
\hline
\end{tabular}

\section{Solution}

Once we have applied all the boundary conditions, then we solve the model for all materials. Every material is solved at each hour of the day. Every hour of the day has a different value of solar irradiance, as presented in table 2 . This is a time-consuming process and needs enormous patience. We are trying to solve for two materials, and each material is solved at almost nine (9) chosen time steps of the day. After we get all the results from CFD, then we import the output of CFD solutions as the input of Structural Analysis, and Structural Analysis also needs to 
be solved for each hour of the day.

Results

After finishing the solution of our model, we can examine different results. Here we need to discuss all results obtained. The results are obtained from two solvers.

1. Computational Fluid Dynamics Analysis

2. Structural Analysis

Table 3. CFD results.

\begin{tabular}{lll}
\hline Time & ${\text { Copper }\left(\text { Outlet }^{\circ} \mathbf{C}\right)}$ Aluminum $\left(\right.$ Outlet $\left.^{\circ} \mathbf{C}\right)$ \\
\hline 9:00 & 55.71 & 54.67 \\
10:00 & 63.69 & 62.53 \\
11:00 & 72.15 & 71.43 \\
$12: 00$ & 74.4 & 73.65 \\
13:00 & 79.3 & 77.95 \\
14:00 & 76.44 & 75.67 \\
15:00 & 69.83 & 68.03 \\
16:00 & 58.53 & 57.15 \\
17:00 & 46.27 & 45.47 \\
\hline
\end{tabular}

\section{Computational Fluid Dynamics (CFD) Analysis}

Computational Fluid Dynamics, usually known as CFD, is performed using ANSYS Fluid Software. CFD analysis is performed on two selected materials, and the focus is to evaluate the performance for each of these selected materials separately. In this section, we will be discussing each material's performance individually. The material used as the materials for the collector's plate and pipes is Copper and Aluminum.

As we can see in this result in table 3, the difference between outlet temperatures is evident but not so huge. Still, as mentioned before in materials property data, we can see the thermal conductivity of copper is almost double the thermal conductivity of aluminum. Also, the specific heat of aluminum is nearly double the specific heat of copper. So as per definitions of both these terms, the question arises is "Why aluminum having the thermal conductivity value half as copper can have almost the same outlet temperature as copper?" Now to elaborate on this answer, we need some understanding of this field. There is a term called "Thermal diffusivity." Which is defined as:

$$
\alpha=\frac{k}{\rho C_{p}} \#(01)
$$

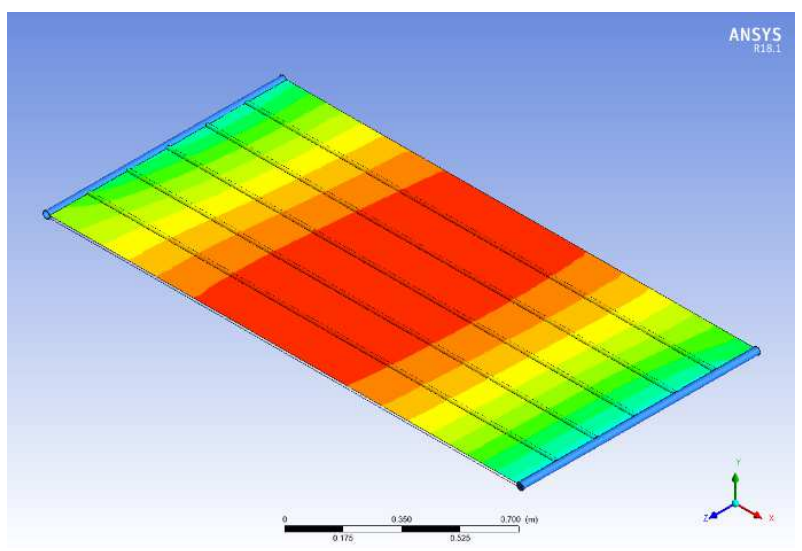

Figure 5. Top Surface CFD Result.
Thermal diffusivity relates both these terms (Thermal Conductivity and Specific Heat) with the density of the material. If we have a look at this property of both the materials, we can see there is not much difference in the value of these properties and which is the reason for this almost the same outlet temperature. Still, the question arises, if the materials can perform almost the same in the heat transfer department so why we don't usually see solar collectors with aluminum?

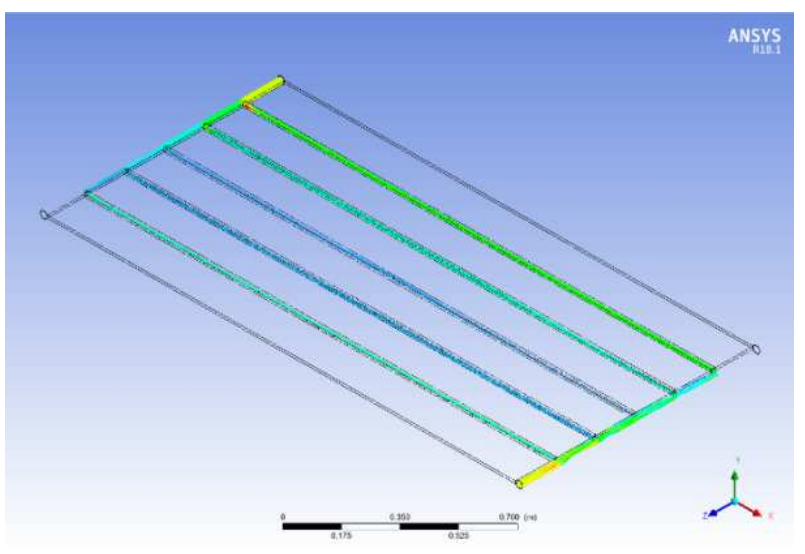

Figure 6. Streamlines.

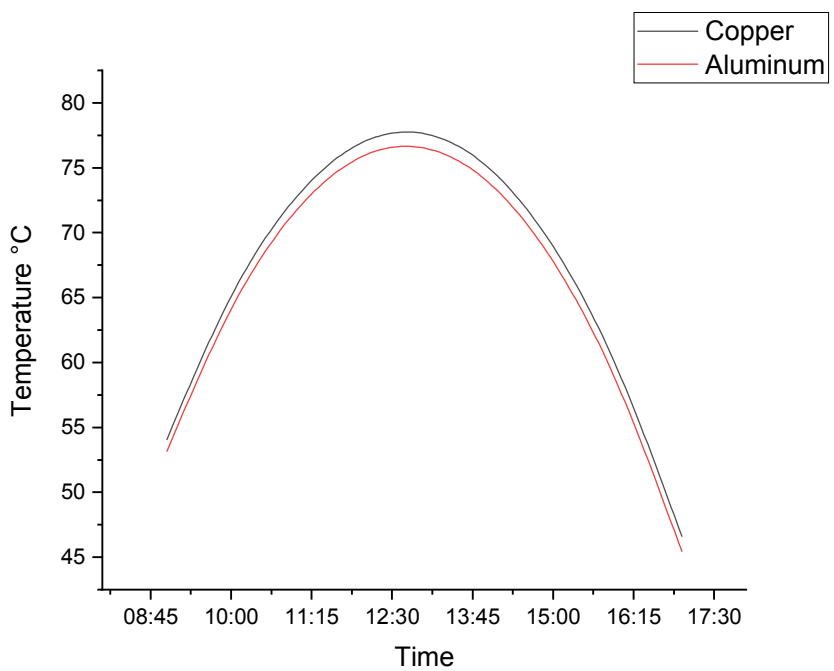

Figure 7. Comparison of Copper and Aluminum outlet Temperatures.

\section{Structural Analysis}

Structural Analysis is done by using ANSYS Structural Software. First, we import the temperature and pressure from CFD Analysis to Structural Analysis to analyze the structural performance of both materials. In this case, because the velocity of water is not so much, so the pressure is low. If we were to use equations to measure the deformation, we could neglect the pressure, but in this paper, we used software to analyze this, so it is included. Temperature is an important parameter which is the reason for deformation. The temperature at the surface of the plate is varying due to the varying heat flux, and for both materials at any given time, the temperature is different due to the properties of materials. In this Analysis, no other load is applied other than pressure and temperature, so all these deformations are because of temperature. 


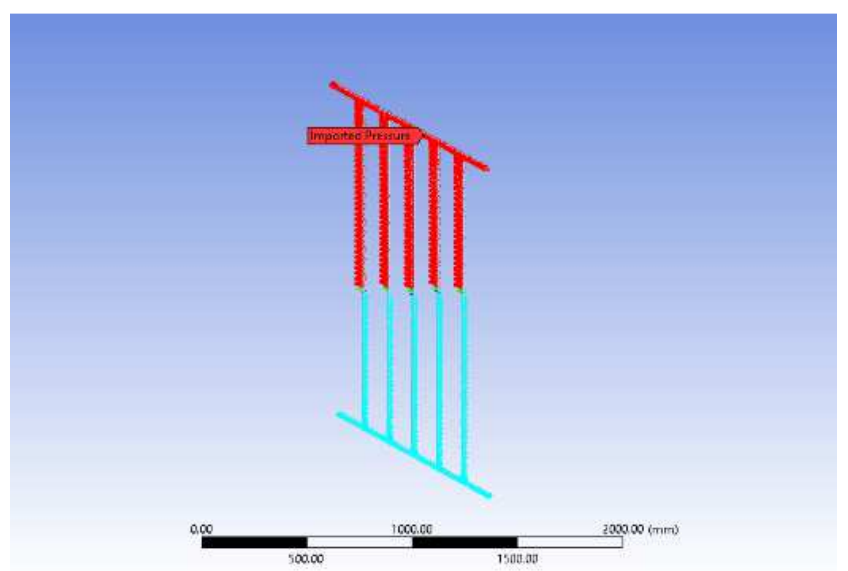

Figure 8. Imported Temperature.

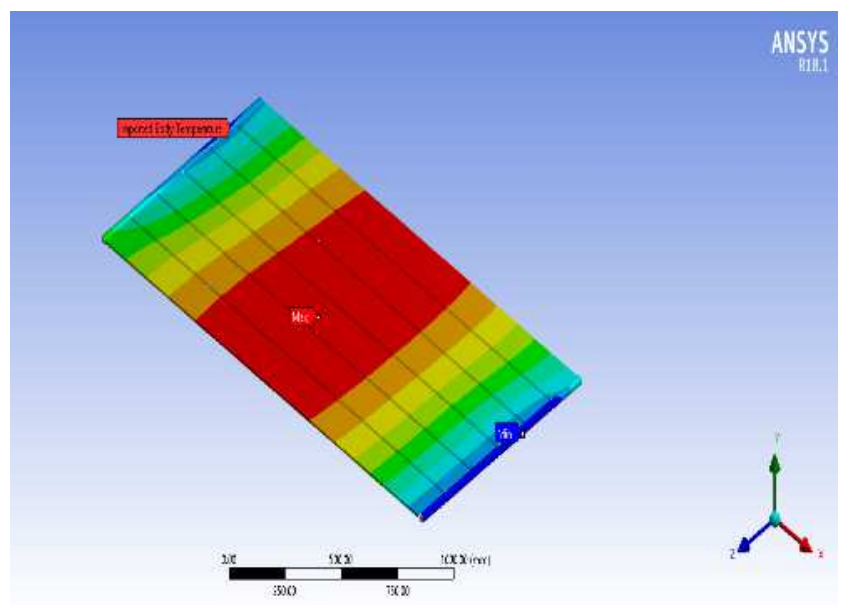

Figure 9. Imported Pressure.

These pictures show the imported pressure and temperatures from CFD Analysis. The imported temperature is at the top surface of the collector, which is designed to absorb solar energy. Structural Analysis tells about the deformation, and our structure can have at any given time of day. It can be seen Aluminum has much more deformation as compared to copper. During analyzing this condition, some parameters are neglected, like wind pressure and some other conditions. It is predicted that in actual cases, some can see much more deformation.

In this application, metal is always in contact with water, so corrosion is also an essential parameter regarding the life of the collector. Another critical parameter in this application is the manufacturing of a solar collector. During the manufacturing of solar collectors, many manufacturing processes are required to join different parts together to form a required shape, and this reduces the usage of aluminum in this application. Welding is a necessary process to manufacture the web of pipes, and welding of aluminum is difficult to accomplish. If some want to use aluminum in this application, some unique process will be required to manufacture the required shape, which will be costly and increase the overall cost of the product.

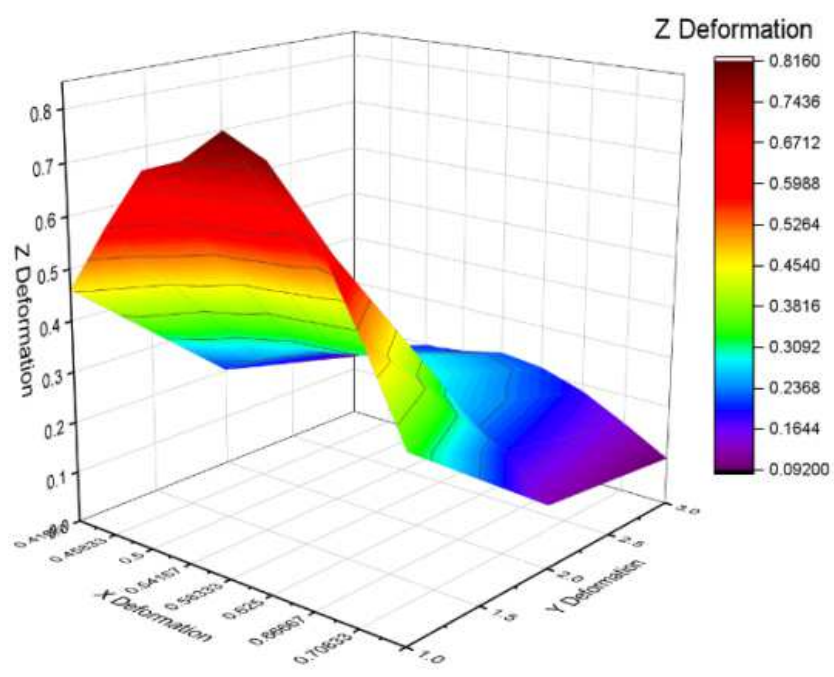

Figure 10. Deformation (Copper).

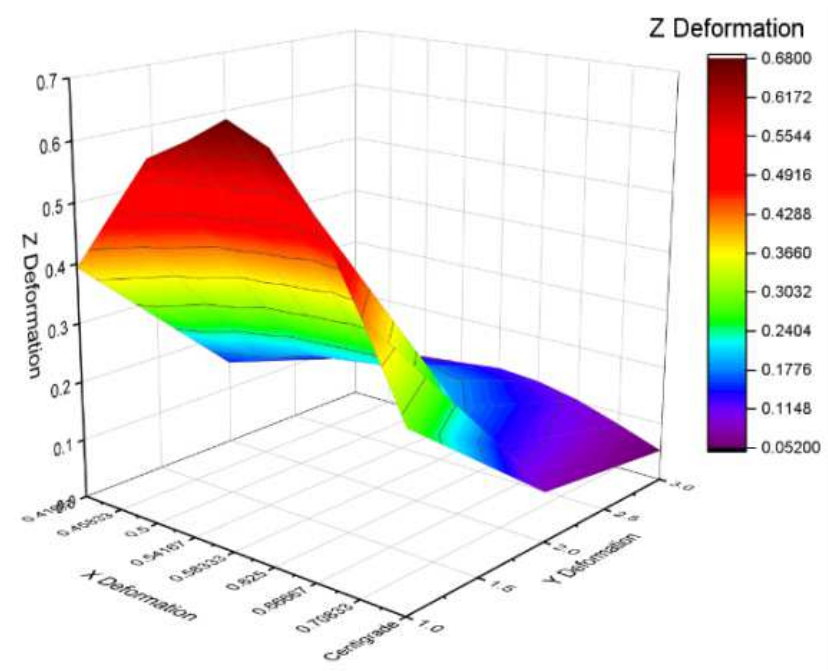

Figure 11. Deformation (Aluminum).

Table 4. CFD results (Surface Temperature).

\begin{tabular}{lll}
\hline Heat Flux & $\begin{array}{l}\text { Maximum Temperature at } \\
\text { Surface (Copper) }\end{array}$ & $\begin{array}{l}\text { Maximum Temperature } \\
\text { at Surface (Aluminum) }\end{array}$ \\
\hline 621.7 & 62.174 & 70.264 \\
750.51 & 71.827 & 78.232 \\
879.5 & 81.692 & 89.196 \\
909 & 85.162 & 92.018 \\
948 & 89.338 & 97.425 \\
909.5 & 86.311 & 94.048 \\
790 & 77.929 & 84.671 \\
597.5 & 64.684 & 69.786 \\
357 & 49.884 & 52.937 \\
\hline
\end{tabular}

In this given table 4, the maximum temperature available at the surface of the specific material is shown. Where it can be seen, Aluminum has more temperature than copper due to its thermal properties. 


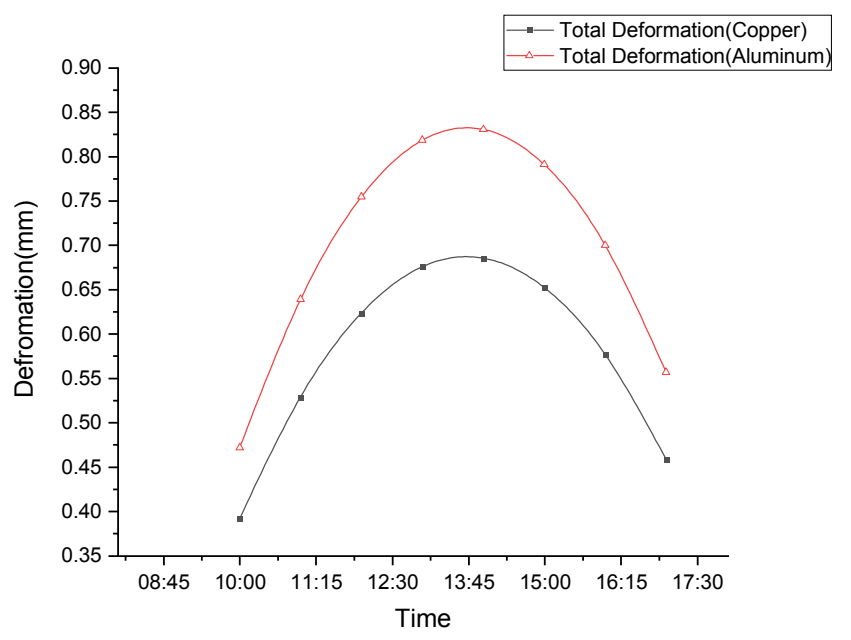

Figure 12. Total Deformation.

\section{Conclusion}

In this paper, the overall performance of flat plate solar collectors is analyzed under certain conditions and assumptions. At first, Computational Fluid Dynamic (CFD) analysis is performed to determine heat transfer capabilities of chosen materials, and output temperature was derived from this Analysis at each chunk of time. After CFD, Structure analysis was performed to see the sustainability of material and structure under certain conditions. Deformations and prediction of life of the structure were the possible outcomes of structural Analysis. After performing both analyses upon both chosen materials (Copper \& Aluminum), it was clear that the heat transfer capabilities of aluminum are almost the same as copper. The sustainability of aluminum is much lower than copper. The actual difficulty is the manufacturing process. Copper can be welded, and the shape of pipes web can be manufactured much easily as compared to aluminum. Using aluminum is much costly. Life of aluminum as pipe material in the solar collector is not, which is needed. So this paper explains the heat transfer problem and structural analysis results. This paper demonstrates a unique way to estimate the performance of flat plate solar collectors, which is challenging to analyze in labs and takes much time.

This paper laid the base for such future Analysis. In the future, there are many problems to be evaluated, such as different mass flow rates or velocities can be analyzed to see at which the mass flow rate and the heat transfer rate is maximum. Further, different designs and materials can be used to analyze the performance.

\section{References}

[1] M. Hissouf, M. Feddaoui, M. Najim, and A. Charef, "Performance of a photovoltaic-thermal solar collector using two types of working fluids at different fluid channels geometry," Renew. Energy, vol. 162, pp. 1723-1734, 2020.
[2] R. Gopi, P. Ponnusamy, A. F. Arokiaraj, and A. Raji, "Materials Today: Proceedings Performance comparison of flat plate collectors in solar air heater by theoretical and computational method," Mater. Today Proc., no. xxxx, pp. 03,2020

[3] Duffie JA, Beckman WA. Solar Engineering of thermal processes. 4th edition. Hoboken, New Jersey: John Wiley \& Sons, Inc; 2013.

[4] Hotteland HC, Woertz BB. Performance of flat-plate solarheat collectors. Trans ASME 1942; 64:91.

[5] Hottel HC, Whiller A. Evaluation of flat-plate collector performance. (P. I). In: Carpenter EF, editor. Transactions of the Conference on the Use of Solar Energy, 2. Tucson: University of Arizona Press; 1958. p. 74.

[6] Tabor H. Solar Energy Collector Design. In: Transactions of the Conference on the Use of Solar Energy, the Scientific Basis, Tuscon, Arizona, Oct. 31-Nov. 1, 1955, pp. 1-23.

[7] Faizal M, Saidur R, Mekhilef S, Alim MA. Energy, economic, and environmental analysis of metal oxides nanofluid for the flat-plate solar collector. Energy Convers Manag 2013; $76: 162-8$

[8] Sachin Gupta, Sayali Rajale, Falgun Raval, Milan Sojitra, Arunendra Kumar Tiwari, Asim Joshi, Ramkishore Singh. Comparative performance analysis of flat plate solar collectors with and without aluminium oxide-based nano-fluid. Materials Today: $\quad$ Proceedings, 2020. https://doi.org/10.1016/j.matpr.2020.08.797

[9] Manufacturing Engineering Society International Conference 2017, MESIC 2017, 28-30 June.

[10] Z. Jun, M. Ayaz Akbar, T. Manzoor, A. Ali, and M. Amjad, "CFD Analysis of Circular Pipe Flat Plate Solar Collector," Int. J. Emerg. Trends Sci. Technol., vol. 04, no. 10, pp., 62666271 .

[11] A. A. Hachicha, I. Rodríguez, O. Lehmkuhl and A. Oliva, On the CFD\&HT of the Flow Around a Parabolic Trough Solar Collector Under Real Working Conditions, Energy Proc. 49 (2014) 1379-1390.

[12] Yanjuan Wang, Qibin Liu, Jing Lei, and Hongguang Jin, Performance Analysis of a Parabolic Through Solar Collector with Non-Uniform Solar Flux Conditions, International Journal of Heat and Mass Transfer. 82 (2015) 236-249.

[13] M. Antonelli, A. Baccioli, M. Francesconi, R. Lensi, L. Martorano, Analysis of a low concentration solar plant with compound parabolic collectors and a rotary expander for electricity generation, Energy Procedia 45 (2014) 170-179.

[14] M. Antonelli, A. Baccioli, M. Francesconi, U. Desideri, L. Martorano, Electrical production of a small size Concentrated Solar Power plant with compound parabolic collectors, Renew. Energy 83 (2015) 1110-1118.

[15] P. Horta, J. C. C. Henriques, M. Collares-Pereira, Impact of different internal convection control strategies in a nonevacuated CPC collector performance, Sol. Energy 86 (2012) $1232-1244$ 